\title{
O EFEITO DA DEAMBULAÇÃO NA DURAÇÃO DA FASE ATIVA DO TRABALHO DE PARTO
}

\author{
The Ambulation Effect in the Active \\ Stage Duration of the Labor \\ El Efecto de la Deambulación en la Duración de \\ la Fase Activa del Trabajo de Parto
}

Fabiana Villela Mamede

Flávia Azevedo Gomes
Ana Maria de Almeida

Marislei Sanches Panobianco
Ana Márcia Spanó Nakano

\begin{abstract}
Resumo
0 trabalho teve como objetivo analisar a associação entre a deambulação e a duração da fase ativa do trabalho de parto. Metodologia: estudo analítico de intervenção do tipo quase experimental. Fizeram parte do estudo 80 parturientes primíparas, admitidas em trabalho de parto espontâneo, no início da fase ativa. Instrumentos de coleta de dados: podômetro para medir a distância percorrida em metros, Escala Visual Numérica (EVN) de dor, formulário para o registro de dados. Resultados: as participantes percorreram uma distância média de 1.624 metros, 63,09\% da fase ativa do trabalho de parto e em um tempo médio de 5 horas. Verificou-se que a quantidade deambulada durante as três primeiras horas da fase ativa está associada a um encurtamento do trabalho de parto, sendo que a cada 100 metros percorridos ocorreu uma diminuição de 22 minutos na primeira hora, 10 minutos na segunda hora e 6 minutos na terceira hora.
\end{abstract}

Palavras-chave: Trabalho de Parto. Dor. Deambulação.

\section{Abstract}

This study aimed to analyze the association between walking and the duration of the active phase of labor. Methodology: We realized an analytic, an almost experimental intervention study. Study participants were 80 primiparous parturient women, who were admitted during spontaneous labor, at the start of the active phase. Data collection instruments: podometer to measure the distance walked in meters, numerical visual pain scale, and form for data registration. Results: the parturient women walked an average distance of 1624 meters, $63.09 \%$ of the active phase of labor and during an average time of 5 hours. We observed that the distance walked during the first three hours of the active phase is associated with a shorter labor time. For every 100 meters walked, duration decreased by 22 minutes during the first hour, by 10 minutes during the second hour and by 6 minutes during the third hour.

\section{Resumen}

La finalidad de este trabajo fue la de analizar la asociación entre la deambulación y el tiempo de la fase activa del trabajo de parto. Metodología: estudio analítico de intervención del tipo casi experimental. Participaron del estudio 80 parturientes primíparas, admitidas en trabajo de parto espontáneo, en el inicio de la fase activa. Instrumentos de recopilación de datos: podómetro para medir la distancia transcurrida en metros, Escala visual numérica de dolor, Formulario para el registro de datos. Resultados: las participantes transcurrieron una distancia media de 1624 metros, $63,09 \%$ de la fase activa del trabajo de parto y en un tiempo promedio de 5 horas. Se verificó que la cantidad deambulada durante las tres primeras horas de la fase activa está asociada a un acortamiento del trabajo de parto. Para cada 100 metros transcurridos ocurrió una disminución de 22 minutos en la primera hora, 10 minutos en la segunda hora y 6 minutos en la tercera hora. 


\section{INTRODUÇÃO}

A incorporação da posição deitada ou reclinada no processo de parturição foi acentuada, especialmente, com a adesão ao parto hospitalar, quando houve um aumento no número de hospitais-maternidades, em que as mulheres eram admitidas em trabalho de parto e colocadas em posição litotômica, permanecendo deitadas durante todo o processo ${ }^{1}$.

0 fortalecimento de tal prática se deu à medida que se adotaram muitas intervenções obstétricas, tais como 0 monitoramento eletrônico fetal, infusão de ocitocina e anestesia epidural, que exigiam a manutenção das mulheres deitadas e estáticas durante o trabalho de parto.

Nos últimos 30 anos, começam as discussões acerca das desvantagens da posição dorsal no trabalho de parto, ressaltando-se as vantagens da mobilidade da mãe e da postura ereta nesse processo. Estas discussões são lideradas, inicialmente pelo obstetra uruguaio Caldeyro-Barcia e seu grupo em Montevidéu, que têm se dedicado a demonstrar as evidências científicas em obstetrícia. Tais pesquisadores demonstraram a interferência da posição materna, na evolução do parto, especialmente nos períodos de dilatação e parto, sobre o grau de bem-estar da mãe e seus efeitos no feto, nos períodos de dilatação e parto. Todavia, apesar da evidência concreta das vantagens da postura ereta e da mobilidade materna, as idéias preconcebidas e os costumes continuaram a prevalecer, com predomínio da posição dorsal, independente do desejo da parturiente ${ }^{1}$.

Estudos têm revelado que, fisiologicamente, é muito melhor para a mãe e para o feto quando a mulher se mantém em movimento durante o trabalho de parto, pois o útero contrai-se muito mais eficazmente, o fluxo sangüíneo que chega ao bebê através da placenta é mais abundante, o trabalho de parto tornase mais curto e a dor é menos intensa ${ }^{2-7}$. Acresce-se o fato de que, na posição supina, a adaptação da apresentação fetal ao estreito da bacia estará facilitada pela postura materna, e, assim, pode-se prevenir complicações do trajeto.

A importância dessa posição é fundamentada em alguns aspectos, envolvendo, especialmente, os seguintes mecanismos: ação da gravidade, compressão dos grandes vasos maternos, aumento dos diâmetros do canal de parto, ângulo de encaixe, ventilação pulmonar e equilíbrio ácido-básico, além da eficiência das contrações uterinas ${ }^{7-8}$.

A posição vertical assumida pela parturiente tem ganhado destaque na assistência ao parto humanizado por produzir melhor efeito na progressão do trabalho de parto devido à melhor circulação uterina, permitindo que as fibras musculares cumpram com sua função contrátil de maneira eficiente ${ }^{8}$.

Estudos vêm revelando que a duração do trabalho de parto pode também estar relacionada à posição, bem como a deambulação que a parturiente assume durante 0 trabalho de parto e parto ${ }^{2,8-10 .}$

A duração diminuída do trabalho de parto em mulheres que deambulavam foi atribuída à melhora na contratilidade uterina, à necessidade diminuída de uso de ocitocina e de analgesia, além de menor freqüência de parto vaginal instrumental como fórceps, extração a vácuo, episiotomia, entre outros ${ }^{2}$.

A literatura revisada sobre a deambulação e posições assumidas pela mulher no trabalho de parto e parto aponta uma série de vantagens e benefícios para a mãe e filho, como descritos anteriormente. Tais evidências nos permitem concordar com autores que chamam a atenção para o fato de que a liberdade de posição e a deambulação da parturiente em todo o desenrolar do trabalho de parto são formas de cuidado que provavelmente são benéficas à parturiente e que devem ser encorajadas ${ }^{11-12}$.

No entanto, restam ainda dúvidas sobre em que medida a deambulação é capaz de produzir tais benefícios. Ou seja, o nosso questionamento se dirige para saber, em termos objetivos, como deve ser a deambulação para obter benefícios durante o trabalho de parto.

Este trabalho teve como objetivo avaliar o efeito da deambulação na duração da fase ativa do trabalho de parto.

Acreditamos que a objetivação dessa medida irá acrescentar conhecimento sobre o papel da deambulação no trabalho de parto e parto, como também auxiliará os profissionais na determinação de orientações sobre o estímulo à deambulação, na condução do trabalho de parto.

\section{MATERIAL E MÉTODO}

Este é um estudo analítico de intervenção, tipo quaseexperimental, em que cada sujeito foi controle dele mesmo. Foi realizado em uma maternidade filantrópica, situada na região sul da cidade de São Paulo. A instituição é credenciada pelo Ministério da Saúde e presta assistência a gestantes e parturientes de toda a cidade de São Paulo, com uma média 1.100 partos mensais. A assistência ao parto normal é feita preferencialmente por enfermeiras obstétricas e/ou obstetrizes.

Foram incluídas no estudo todas as 80 primigestas que se internaram no Centro de Parto Normal da referida instituição, no período diurno, de segunda a sexta-feira, nos meses de julho e agosto de 2004, com idade gestacional de 37 a 42 semanas, gestação única e tópica, ausência de intercorrência gestacional, feto vivo em apresentação cefálica de vértice, com boas condições de vitalidade, presença de líquido amniótico claro constatado na amnioscopia, apresentando duas ou mais contrações de intensidade média a cada 10 minutos e/ou dilatação cervical de 3 a $5 \mathrm{~cm}$.

Foram respeitados os preceitos éticos da Pesquisa com Seres Humanos.

Para a coleta de dados utilizaram-se dois instrumentos, um aparelho denominado podômetro e um formulário de registro de dados.

0 podômetro é um contador digital utilizado para medir a distância percorrida, contendo dois pares de eletrodos, que registra a velocidade média deambulada, o número de passos e a distância percorrida em metros. Este instrumento foi acoplado a um propé e usado pela parturiente durante a deambulação. 
Outro instrumento utilizado foi um formulário com registro de dados demográficos, valores da dilatação cervical, resultados obstétricos e neonatais, e a distância percorrida.

A partir da aquiescência das parturientes em participar do trabalho, foi colocado o podômetro, que permaneceu durante toda a fase ativa do trabalho de parto. 0 trajeto deambulado por elas foi registrado a cada hora, até o final da fase ativa do trabalho de parto. Os dados referentes à avaliação da dilatação cervicouterina e uso de fármacos foram registrados conforme evolução do trabalho de parto e procedimentos realizados pela equipe de profissionais da instituição.

Os dados coletados foram organizados em banco de dados e submetidos a testes estatísticos de Pearson e de Regressão Linear Simples.

\section{RESULTADOS}

Oitenta primigestas em trabalho de parto espontâneo participaram do estudo, sendo $24(30,0 \%)$ brancas e 56 $(70,0 \%)$ não brancas. A idade variou de 15 a 35 anos, com uma média de $21,5 \pm 4,7$ anos, sendo que $34(42,5 \%)$ eram adolescentes. Entre as parturientes, predominou uma baixa escolaridade, com mais da metade delas $(71,4 \%)$ tendo menos de oito anos de educação formal. A maioria era casada ou vivia em união estável $(68,7 \%)$, e $73,8 \%$ não exerciam nenhuma ocupação remunerada.

Das 80 parturientes estudadas, 6 foram submetidas ao parto cesárea, tendo como indicação, para cinco delas, parada ou falta de progressão do trabalho de parto, e para uma, a ocorrência de bradicardia fetal no período expulsivo. Assim, 75 (93,75\%) parturientes completaram a fase ativa do trabalho de parto. 0 tempo de evolução da fase ativa do trabalho de parto destas 75 parturientes variou de 3 a 14 horas, com uma média de 7,66 $\pm 2,41$ horas, conforme se observa na Tabela 1.

\section{Tabela 1:}

Distribuição das parturientes atendidas no Centro de Parto Normal, segundo o intervalo de tempo da evolução da fase ativa do trabalho de parto (horas), durante o período de julho a agosto de 2.004. São Paulo - Brasil.

\begin{tabular}{c|c|c}
\hline $\begin{array}{c}\text { Intervalo de tempo da fase ativa } \\
\text { do trabalho de parto(horas) }\end{array}$ & Freqüência & $\%$ \\
\hline$<6$ & 21 & 28,0 \\
$6-9$ & 32 & 42,7 \\
$9-12$ & 18 & 24,0 \\
$12-14$ & 04 & 5,3 \\
\hline Total & 75 & 100,0 \\
\hline
\end{tabular}

Entre as 80 parturientes, observou-se que $54(67,5 \%)$ fizeram uso de ocitócito; $63(78,7 \%)$ foram submetidas a amniotomia artificial; 48 (64,9\%) realizaram episiotomia, conforme se observa na Tabela 2.

\section{Tabela 2:}

Distribuição das parturientes atendidas no Centro de Parto Normal, segundo o uso de ocitócito, tipo de rompimento da bolsa amniótica, tipos de parto, ocorrência de laceração, ocorrência de episiotomia, durante o período de julho a agosto de 2004. São Paulo - Brasil.

\begin{tabular}{c|c|c}
\hline Resultados obstétricos & Freqüência & $\%$ \\
\hline Uso de ocitócito & 54 & 67,5 \\
Amniotomia espontânea & 17 & 21,25 \\
Amniotomia artificial & 63 & 78,75 \\
Parto cesárea & 6 & 7,5 \\
Parto normal & 74 & 92,5 \\
Períneo íntegro & 12 & 16,2 \\
Laceração de $1^{\circ}$.grau de períneo & 12 & 16,2 \\
Episiotomia & 48 & 64,9 \\
Laceração + episiotomia & 2 & 2,7 \\
\hline
\end{tabular}

Em relação aos resultados neonatais, 79 (98,7\%) dos recémnascidos, após avaliação no quinto minuto de vida, tiveram Índice de Apgar maior ou igual a sete, o que, segundo parâmetros dessa avaliação, representa boas condições de vitalidade.

\section{Deambulação durante a fase ativa do trabalho de parto}

A distância total percorrida durante toda a fase ativa do trabalho de parto variou de 101 a 3.736 metros, com uma média de 1.624,57 $\pm 836,79$ metros.

0 percurso realizado foi maior na primeira hora da fase ativa do trabalho de parto, com uma média de 557,9 \pm 305,8 metros, decrescendo com o passar das horas. Durante as três primeiras horas do trabalho de parto, praticamente todas as parturientes deambularam, sendo que após esta hora ocorreram nascimentos, tendo então diminuição do número amostral. Após as 9 horas do início da fase ativa as parturientes não deambularam mais.

A interrupção da deambulação deu-se por volta de 5,0 \pm 1,74 horas, $63,09 \%$ do tempo da fase ativa do trabalho de parto, com as parturientes apresentando uma dilatação cervical média de 8,36 $\pm 1,33 \mathrm{~cm}$.

Entre as parturientes estudadas, não houve correlação entre a distância percorrida durante a fase ativa do trabalho de parto, idade e ganho de peso ponderal durante a gestação. (Teste de Correlação de Pearson $-r=-0,071, p=0,532 ; r$ $=-0,056, p=0,621$, respectivamente).

0 teste de correlação entre a distância percorrida durante toda a fase ativa do trabalho de parto e a duração da mesma demonstrou que não houve significância estatística entre tais variáveis (Tabela 3). No entanto, houve diferença significativa nas três primeiras horas da fase ativa do trabalho de parto quando se associou o trajeto percorrido a cada hora dessa fase, ou seja, verificou-se que as parturientes que deambularam uma distância maior, durante as três primeiras horas da fase ativa, tiveram uma redução na duração do trabalho de parto, associação essa que deixa de ocorrer a partir da quarta hora (Tabela 3). 
Tabela 3:

Valores das regressões lineares simples realizadas entre a distância percorrida durante o trabalho de parto e o tempo da fase ativa do trabalho de parto das parturientes atendidas no Centro de Parto Normal, durante o período de julho a agosto de 2004. São Paulo - Brasil.

\begin{tabular}{c|c|c|c|c|c|c}
\hline $\begin{array}{c}\text { Momento da } \\
\text { deambulação }\end{array}$ & $\begin{array}{c}\text { Coeficiente } \\
\text { linear }\end{array}$ & $\begin{array}{c}\text { Coeficiente } \\
\text { angular }\end{array}$ & $\begin{array}{c}\text { Coeficiente de } \\
\text { determinação }\end{array}$ & $\begin{array}{c}\text { Intervalo de } \\
\text { confiança de } \\
95 \%\end{array}$ & Valor do p & $\begin{array}{c}\text { Número de } \\
\text { observações }\end{array}$ \\
\hline $\begin{array}{c}\text { Durante toda a fase ativa } \\
\text { do trabalho de parto }\end{array}$ & 466,59 & 0,0018 & 0,01 & $-0,038$ a 0,041 & 0,927 & 75 \\
Primeira hora & 590,06 & $-0,2161$ & $-0,45^{*}$ & $-0,316$ a- 0,1167 & 0,000 & 75 \\
Segunda hora & 566,80 & $-0,096$ & $-0,37^{*}$ & $-0,151$ a $-0,041$ & 0,001 & 75 \\
Terceira hora & 557,36 & $-0,061$ & $-0,31^{*}$ & $-0,105$ a $-0,018$ & 0,007 & 74 \\
Quarta hora & 535,29 & $-0,030$ & $-0,18$ & $-0,070$ a 0,009 & 0,126 & 69 \\
Quinta hora & 576,8263 & $-0,027$ & $-0,21$ & $-0,062$ a 0,008 & 0,130 & 54 \\
Sexta hora & 584,0622 & $-0,0133$ & $-0,12$ & $-0,047$ a 0,020 & 0,431 & 45 \\
Sétima hora & 609,1152 & $-0,013$ & $-0,12$ & $-0,049$ a 0,023 & 0,477 & 37 \\
\hline
\end{tabular}

Para estimar a redução da fase ativa do trabalho de parto nas três primeiras horas, utilizou-se o Teste de Regressão Linear, verificando-se que, na primeira hora, a cada 100 metros deambulado, a duração da fase ativa do trabalho de parto teve uma redução de cerca de 22 minutos, revelando que a deambulação nesta primeira hora favoreceu uma diminuição na fase ativa de 2,04 horas. Na segunda hora, a redução na duração desta fase foi de 10 minutos a cada 100 metros deambulado, levando, portanto, a uma diminuição de 1,67 hora na duração total do trabalho de parto. Na terceira hora, a redução desta fase foi de 6 minutos para cada 100 metros deambulado. Assim, a redução desta fase foi de 1,34 hora.

No que se refere à ruptura das membranas amnióticas, verificouse que entre as 63 mulheres que se submeteram à amniorrexe artificial, $58(92,06 \%)$ delas completaram a fase ativa do trabalho de parto e tiveram um trajeto médio deambulado, durante toda esta fase de 1.605,55 $\pm 858,10$ metros, sendo que a duração da fase ativa do trabalho de parto para essas parturientes foi de 8,04 horas, em média. Este procedimento foi realizado por volta de $58,75 \%$ do tempo de trabalho de parto com dilatação cervical média de $6,3 \pm 1,4 \mathrm{~cm}$ no momento da ruptura.

As $17(21,25 \%)$ parturientes que tiveram a ruptura espontânea das membranas amnióticas percorreram, durante toda a fase ativa do trabalho de parto, um trajeto médio de 1.695,06 \pm 772,83 metros. A duração da fase ativa do trabalho de parto foi uma média de 7,04 horas. Este procedimento ocorreu, por volta de $56,87 \%$ do tempo de trabalho de parto, com uma dilatação cervical média de 5,8 $\pm 2,1 \mathrm{~cm}$ durante o rompimento.

Quanto ao uso de ocitócito, foi possível verificar que as 54 $(67,5 \%)$ parturientes que fizeram uso dessa droga percorreram uma distância média de 1.696,22 \pm 883,41 metros.

Destas 54 pacientes em que se administrou ocitócito, 5 delas não completaram a fase ativa do trabalho de parto, em decorrência da falta de progressão ou parada do trabalho de parto, sendo submetidas à cesariana. As 49 parturientes que completaram a dilatação cervical tiveram um tempo médio de 8,31 $\pm 2,35$ horas de fase ativa do trabalho de parto. A dilatação cervical média, quando se iniciou a infusão de ocitócito, era 4,65 $\pm 1,27 \mathrm{~cm}$.
As $26(32,5 \%)$ parturientes que não fizeram uso de ocitócito percorreram uma distância média de 1.532,49 \pm 800,14 metros, durante a fase ativa do trabalho de parto, e completaram esta fase em 6,46 $\pm 2,08$ horas.

A avaliação do efeito da deambulação e da ruptura da bolsa amniótica, quer seja espontânea ou artificial, e com o uso de ocitócito, aponta que tais variáveis (ruptura espontânea ou artificial das membranas amnióticas e uso de ocitócito) não tiveram significância em relação à duração da primeira fase do trabalho de parto.

Vale reforçar que todas as parturientes, mesmo fazendo uso de ocitócito e/ou com amniotomia espontânea ou artificial, eram estimuladas a deambular. E quando as mesmas se recusavam, permaneciam no leito.

\section{Discussão}

A todas as parturientes foi garantida a liberdade para interromper a deambulação quando desejassem; entretanto, observou-se entre elas um maior potencial de adesão para a deambulação no trabalho de parto do que participantes de outros estudos ${ }^{2,13}$. Ao serem incluídas no estudo, 100\% das parturientes estudadas atenderam ao estímulo à deambulação contra os $84 \%$ de atendimento no estudo de Bloom et al. ${ }^{2} \mathrm{~A}$ adesão obtida neste estudo pode estar relacionada ao suporte oferecido, uma vez que uma das pesquisadoras acompanhouas em toda a fase ativa do trabalho de parto, estimulando-as a deambular efornecendo orientações sobre o processo de parturição. Uma melhor adesão à deambulação se dá pelo estímulo oferecido às parturientes durante todo o trabalho de parto, seja por um acompanhante, pelo marido ou por uma enfermeira obstétrica ${ }^{13}$.

Comparando os achados do presente estudo com os de Bloom et al. ${ }^{2}$, que utilizaram o podômetro como instrumento de registro de medidas, computando o número de passos dados pelas participantes, e não a distância em metros, verifica-se que a distância média percorrida pelas participantes deste estudo (1.624 \pm 836 metros) foi superior à encontrada por aqueles autores (337,33 \pm 488,6 metros) ${ }^{2}$.

Um outro achado que chama a atenção, quando se comparam os resultados com os de Bloom et al. (1998), refere- 
se ao percentual de $21,7 \%$ de participantes daquele estudo que não se movimentou durante o trabalho de parto, mesmo tendo optado por fazer parte do grupo que deambulava². Neste estudo, todas as parturientes deambularam durante a fase ativa do trabalho de parto, sendo que o menor trajeto deambulado foi de 101 metros, e apenas nove $(12,0 \%)$ participantes tiveram um trajeto total deambulado semelhante ao valor médio alcançado pelos autores referidos acima (até 337 metros deambulados). Assim, 71 (88,7\%) parturientes estudas excederam à distância deambulada daquelas, e esse fato pode ser considerado um elemento motivador para continuidade de estudos que buscam uma melhor compreensão dos benefícios dessa prática.

Outro dado de relevância observado nesse estudo referese ao fato de que $57,5 \%$ das participantes interromperam a deambulação somente quando apresentaram uma dilatação cervical média de $8,36 \pm 1,33 \mathrm{~cm}$, momento em que já se encontravam em fase de transição para o segundo período do trabalho de parto. Tais achados contrapõem-se à afirmativa de vários autores de que a partir da segunda metade da primeira fase do trabalho de parto as parturientes cansam-se e desmotivam-se para deambular ${ }^{2,13,14}$. Observamos, ainda, que, do ponto de vista de tempo de deambulação, as parturientes estudadas deambularam em um tempo médio de $5 \pm 1,74$ horas ou $300 \pm 104,58$ minutos, valor superior aos $64 \pm 34$ minutos encontrados por Frenea et al. ${ }^{13}$

Estudos que pesquisaram o tempo deambulado pelas parturientes durante o trabalho de parto concluíram que as mulheres deambulavam 2,2 horas ou $54 \%$ da primeira fase do trabalho de parto $^{15}$. No presente estudo observou-se que as parturientes deambularam uma média de $63,09 \%$ da primeira fase do trabalho de parto, contando a partir do início da fase ativa do parto.

Os resultados do presente estudo permitem verificar que a distância percorrida nas três primeiras horas da fase ativa do trabalho de parto esteve associada à redução no tempo desta fase. Esta redução foi de 22 minutos, 10 minutos e 6 minutos a cada 100 metros deambulado, na primeira, segunda e terceira hora, respectivamente, apontando para uma redução média de 2,04 horas, 1,67 hora e 1,34 hora, respectivamente às três primeiras horas da fase ativa do trabalho de parto, entre as parturientes estudadas.

Para acelerar o trabalho de parto, a infusão intravenosa de ocitocina, em combinação com a ruptura artificial das membranas amnióticas na fase ativa do trabalho de parto, tem sido empregada tradicionalmente. 0 emprego destas intervenções no trabalho de parto é, freqüentemente, denominado de manejo ativo do trabalho de parto ${ }^{16-17}$.

Considerando que tem sido reforçada a idéia de que o uso de ocitócito bem como o rompimento da bolsa amniótica diminuem a duração da fase ativa do trabalho de parto, e que 54 $(67,5 \%)$ das parturientes deste estudo fizeram uso de ocitócito e $100 \%$ tiveram a bolsa rompida na fase ativa do trabalho de parto, realizaram-se testes estatísticos, a fim de avaliar se estas variáveis poderiam estar influenciando nos resultados deste estudo.

A deambulação tem um papel extremamente importante em todo o transcorrer do processo de parturição. Os ossos da pelve são destinados a proteger e guiar o feto no momento em que ele estiver nascendo. A bacia óssea é mantida por um sistema de ligamentos, os quais, durante a gravidez, afrouxamse devido à influência do hormônio relaxina. Por conta deste relaxamento, há uma maior flexibilidade das articulações pélvicas, e, por conseguinte, aumenta significantemente 0 espaço no interior da bacia pélvica, especialmente quando a parturiente se movimenta e muda a posição corporal ${ }^{5}$.

A mulher permanecendo na posição vertical faz com que suas pernas funcionem como uma alavanca para a pelve, o que facilita a abertura da passagem/estreito inferior da pelve, tornando-a uma passagem mais fácil para o feto. Dessa maneira, favorece um aumento de $28 \%$ no espaço interior do estreito inferior da bacia pélvica ${ }^{5}$.

Quando a parturiente está em uma posição vertical, ela muda a curvatura do sacro e o ângulo da parte do feto se apresenta criando uma curvatura sacral em C, em vez de $S$ (como quando se está deitada), o que facilita para o feto avançar na pelve ${ }^{18}$. Concomitantemente a isso, um outro mecanismo favorece a descida fetal. Trata-se daquele mecanismo em que os ossos da cabeça fetal são capazes de se moldarem em resposta a um ajuste rígido com que a apresentação se depara. Estes dois mecanismos acontecem a fim de tornar 0 nascimento do feto tão seguro quanto possível, e, por outro lado, a preferência das mulheres por uma postura vertical demonstra suas capacidades instintivas para buscar maneiras fáceis e efetivas de dar à luz ${ }^{5}$.

\section{Conclusões}

Durante toda a fase ativa do trabalho, o pesquisador permaneceu com as 80 parturientes estimulando a deambulação, e, mesmo tendo a liberdade para interromper, elas percorreram uma distância média de 1.624,57 metros, representando $63,09 \%$ da fase ativa do trabalho de parto e em um tempo médio de 5 horas. Tais achados reforçam a importância do estímulo oferecido às parturientes, durante todo o trabalho de parto, seja por um acompanhante, pelo marido ou por um profissional de saúde.

Do ponto de vista clínico, os resultados do presente estudo trazem importantes contribuições ao evidenciar o relevante papel da deambulação nas primeiras horas da fase ativa do trabalho de parto. De um modo geral, verificamos a presença de associação quando a deambulação ocorre nas três primeiras horas da fase ativa. Constatamos, portanto, que a maior influência da deambulação sobre a duração do trabalho de parto está na primeira, segunda e terceira hora de deambulação, ou seja, quanto mais as mulheres deambularem nestas três horas de início da fase ativa do parto, são maiores os benefícios percebidos para redução da duração do trabalho de parto.

Os resultados deste trabalho, bem como de outros que evidenciam a influência da deambulação no processo de parturição, devem estar disponíveis às mulheres e, em particular, às gestantes e parturientes, de forma a capacitálas a ter familiaridade com essa prática. Essa conscientização pode ajudá-las a tomar decisões sobre a condução do trabalho de parto e parto que se deseja, com a finalidade de realizar o seu plano de parto e tendo como benefício uma melhor condução do trabalho de parto e parto. 


\section{Referências}

1. Dunn PM. Posição materna durante o parto: aspectos históricos e antropológicos In: Sabatino H, Dunn PM, Caldeyro-Barcia R. Parto humanizado: formas alternativas. Campinas (SP): Ed Unicamp; 2000.

2. Bloom SL, Mclntire D, Kelly MA, Beimer HL, Burpo RH. Lack of effect of walking on labor and delivery. N Engl J Med 1998; 339 (2): 76-9.

3. Kitzinger S. Mães um estudo antropológico da maternidade. São Paulo (SP): Martins Fontes; 1978.

4. Osava RH. Assistência ao parto no Brasil: o lugar dos não médicos [tese de doutorado]. São Paulo (SP): Faculdade de Saúde Pública/USP; 1997.

5. Robertson A. Preparing for birth: mothers: background notes for pre-natal classes. $3^{\mathrm{a}}$ ed. Sidney(AU): ACE Graphics; 2000.

6. Mamede MV, Clapis MJ, Matuo YK, Nakano MAS, Almeida AM, Gomes FA,. Atuação da enfermeira obstétrica ao parto normal ruma à maternidade segura-Manual protocolo. Ribeirão Preto (SP); 2000.

7. La Fuente P. Deambulação durante o trabalho de parto e tipos de puxos: sua influência sobre a evolução do parto e o bem estar fetal. In: Sabatino H, Dunn PM, Calder-Barcia R. Parto humanizado: formas alternativas. $2^{a}$ ed. Campinas(SP): Ed Unicamp; 2000.

8. Sabatino H. Vertical position of the mother during labor. RBM : revista brasileira de medicina. Ginecologia e obstetricia 1997 abr; 8(2): 51-64.

9. Mendez-Bauer C, Arroyo J, Garcia Ramos C, Menéndez A, Lavilla M, Izquierdo $\mathrm{F}$, et al. Effects of standing position on spontaneous uterine contractility and other aspects of labor. J Perinat Med 1975; 3: 89-99.

10. Albers $L$, et al. The relationship of ambulation in labor to operative delivery. J Nurse Midwifery 1997; 42 ( 1): 4-8.

11. Piotrowski KA. Nursing care during labor. In: Lowdermilk DL, Perry SE, Bobak IM. Maternity \& women's health care. $17^{\mathrm{a}}$ ed. USA: Mosby; 2000.

12. Sabatino H. Trabalho realizado no grupo de parto alternativo do Departamento de Tocoginecologia da FMC/UNICAMP. Anais do Seminário sobre parto e nascimento no Rio de Janeiro. Rio de Janeiro (RJ): SMS; 1996.
13. Frenea S, Chirossel C, Rodriguez R, Baguet JP, Racinet C, Payen JF. The effects of prolonged ambulation on labor with epidural analgesia. Anesth Analg 2004; 98: 224-29.

14. Stewart P, Spiby H. A randomized study of the sitting position for delivery using a newly designed obstetric chair. Br J Obstet Gynaecol 1989; 96: 327-33.

15. Flynn A, Kelly J, Hollings G, Lysich PJ. Ambulation in labour. Br Med J 1978; 2: 591-99.

16. Thornton JG, Lifford R. Active management of labour: current knowledge and research issues. Br Med J. 1994; 309(6960): 366-69.

17. Organização Mundial de Saúde- OMS. Maternidade segura. Assistência ao parto normal: um guia prático. Genebra(SW): 1996.

18. Biancuzzo M. Six mysths of maternal posture during labor. MCN: Am J Matern Child Nursing 1993; 18: 264-69.

\section{Sobre as Autoras}

\section{Fabiana Villela Mamede}

Escola de Enfermagem de Ribeirão Preto, USP, Ribeirão Preto.

\section{Ana Maria de Almeida}

Escola de Enfermagem de Ribeirão Preto, USP, Ribeirão Preto.

\section{Ana Márcia Spanó Nakano}

Escola de Enfermagem de Ribeirão Preto, USP, Ribeirão Preto.

\section{Flávia Azevedo Gomes}

Escola de Enfermagem de Ribeirão Preto, USP, Ribeirão Preto

\section{Marislei Sanches Panobianco}

Escola de Enfermagem de Ribeirão Preto, USP, Ribeirão Preto 